\title{
Experimental Comparison of Radiant Ceiling Panels and Ceiling Panels Containing Phase Change material (PCM)
}

\author{
Dragos-Ioan Bogatu*, Eleftherios Bourdakis, Ongun Berk Kazanci, and Bjarne W. Olesen \\ International Centre for Indoor Environment and Energy, Department of Civil Engineering, Technical University of Denmark
}

\begin{abstract}
Two commercially available ceiling panels, one metal and one gypsum incorporating microencapsulated PCM were compared experimentally to determine their limitations and ability to provide an adequate indoor thermal environment. The experiments took place from February to May 2018 in a climate chamber at the Technical university of Denmark. In total, seven scenarios were evaluated, five with active cooling, where the flow rate and solar heat gains were varied, and two without. Results showed that according to EN 15251:2007, the RCPs maintained the best indoor thermal environment for $91 \%$ of occupancy time in Category III - operative temperature between $22^{\circ} \mathrm{C}$ and $27^{\circ} \mathrm{C}$, and $75 \%$ in Category II - operative temperature between $23^{\circ} \mathrm{C}$ and $26^{\circ} \mathrm{C}$, for a $140 \mathrm{~kg} / \mathrm{h}$ flow rate and the reference solar heat gains. Alternatively, the PCM panels maintained Category III for only $48 \%$ of the time, while only $30 \%$ in Category II for a $220 \mathrm{~kg} / \mathrm{h}$ flow rate and the reference solar heat gains. The PCM panel presented the ability to store the heat for a later time. However, the PCM panels' solution proved inadequate in terms of heat storage capacity, pipe positioning and thermal conductivity while improvements are required in order to employ them in new and renovated buildings.
\end{abstract}

\section{Introduction}

Phase change materials (PCM) present the ability to store more heat per unit volume due to their latent heat thermal storage [1-4]. Thus, both the indoor thermal environment and energy use of buildings can benefit from PCMs because of their specific temperature range, peak-shaving and load shifting ability $[1,4]$.

Considering these advantages, PCM can be used for both lightweight buildings and retrofitted buildings as it can cover for the reduced thermal mass [3]. In addition, due to its ability to shift the load and because of its large selection of temperature ranges, it can be used as a high temperature cooling system. Therefore, it can help increase renewable energy integration in buildings by making use of night radiative cooling through technologies such as PV/Ts [5,6].

The purpose of this study was to compare experimentally with respect to thermal comfort two different cooling systems, radiant cooling panels (RCP) and gypsum ceiling panels containing microencapsulated PCM, both discharged through water circulation. Through these experiments, an overview of this technology's limitations as well as the panels' cooling behavior and ability to provide a comfortable indoor thermal indoor environment was determined.

\section{Methodology}

Several experiments were carried out from January to May 2018 in a climate chamber, Chamber 6, at the International Centre for Indoor Environment and Energy, Technical University of Denmark.

\subsection{Climate chamber}

The climate chamber had a total area of $22.7 \mathrm{~m}^{2}(4.2 \times 5.4$ $\mathrm{m} \mathrm{W} \mathrm{x} \mathrm{L}$ ) and a height of $2.7 \mathrm{~m}$ designed as a two-person office. Figures 1 and 2 show the chamber and the layout of the heat sources in the chamber.

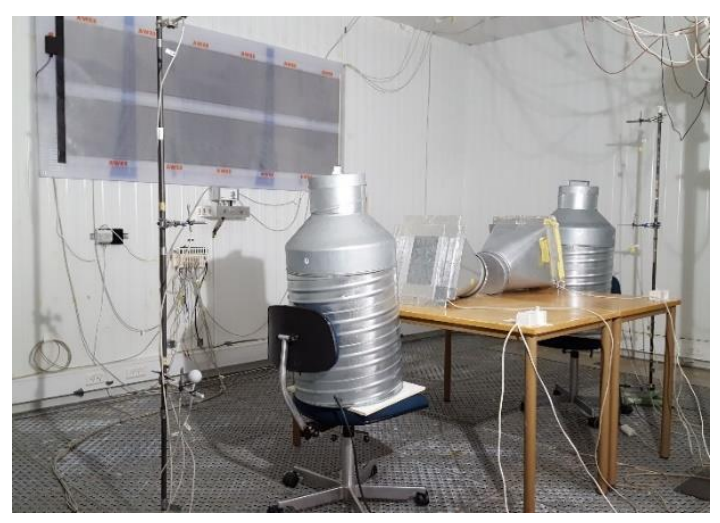

Fig. 1. Chamber 6 .

The chamber had neither external windows nor external walls as it was situated in a bigger hall. Furthermore, the chamber was insulated from the surroundings as all windows were covered with polystyrene for a better insulation while the walls are insulated.

The internal heat loads (Table 1) present in the room were set on a schedule representing working hours from 08:00 to 18:00 where the gains were operating at full capacity. Additionally, as the chamber had no external walls, in reality a $1.5 \mathrm{~m}^{2}$ heating net was used on one side to simulate the solar heat gains from the south present during the day.

\footnotetext{
* Corresponding author: drabo@byg.dtu.dk
} 


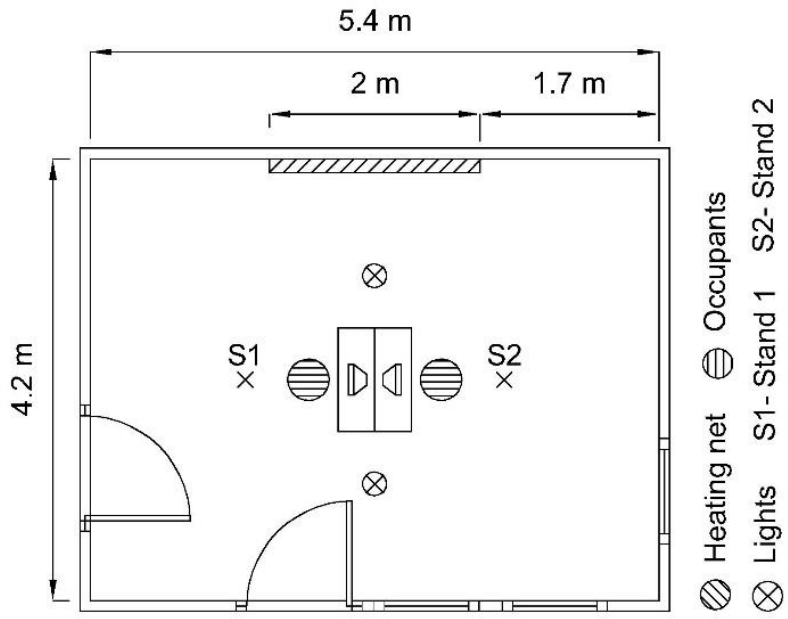

Fig. 2. Office room representation.

Table 1. Internal heat gains.

\begin{tabular}{|c|c|c|c|}
\hline Gains & Units & $\begin{array}{c}\text { Heat Gain Per } \\
\text { Unit }\end{array}$ & $\begin{array}{c}\text { Total Heat } \\
\text { Gain }\end{array}$ \\
\hline- & - & {$[\mathrm{W}]$} & {$[\mathrm{W}]$} \\
\hline Occupant & 2 & 90 & 180 \\
\hline Computer & 2 & 150 & 300 \\
\hline Light & 2 & 10 & 20 \\
\hline Total & 6 & - & 500 \\
\hline
\end{tabular}

The solar heat gains profile (Figure 3) was determined by making an average of the solar heat gains on a south facing wall for the 153 days representing the Danish cooling period ( $1^{\text {st }}$ of May $-30^{\text {th }}$ of September). The data was acquired from the ASHRAE IWEC database for Copenhagen, Denmark [7].

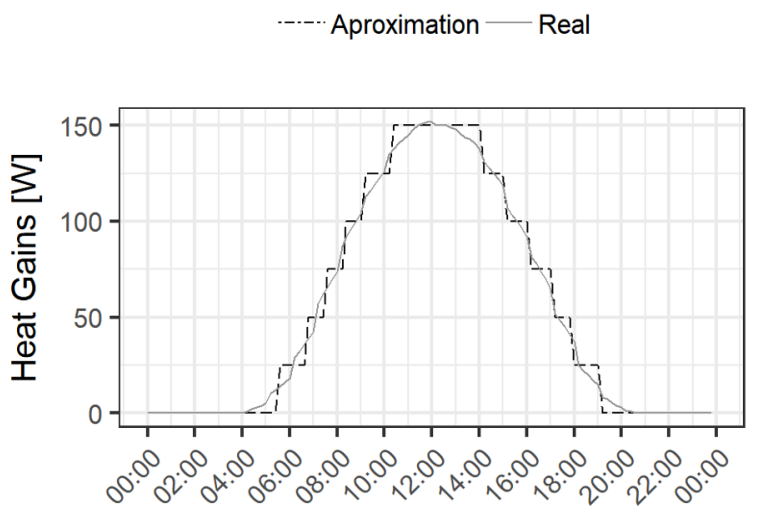

Fig. 3. Solar heat gains processing, SHG1.

The values present in the room, between 0 and $150 \mathrm{~W}$ during the day, were then found by assuming a double glazing window with a $U$-value of $0.53 \mathrm{~W} / \mathrm{m}^{2} \mathrm{~K}$ and a SHGC (solar heat gain coefficient) of 0.283 . Finally, due to the heating net control, the profile found was rounded to steps of $25 \mathrm{~W}$ depending on a predefined schedule.

\subsection{Water supply system}

For both panels, water was supplied to the suspended ceiling from a chiller. Before reaching the loop in the ceiling, the water passed through a system, which regulated the water supply temperature. The system was employed in order to keep the supply temperature, $\mathrm{T}_{\text {supply }}$ at $18^{\circ} \mathrm{C}$ for all scenarios. Still, that was not the case, as the system provided water at a temperature around $20^{\circ} \mathrm{C}$.

According to the schedule, water was pumped to the ceiling. Two manifold pipes positioned in the suspended ceiling on each side of the room (top and bottom hashed area-Figure 4) ensured an even distribution of cold water over the surface of the ceiling. The water was then circulated in a supply-return circuit over every two columns. Furthermore, the middle column is not part of the water circulation system as it was designated for lighting and ventilation.

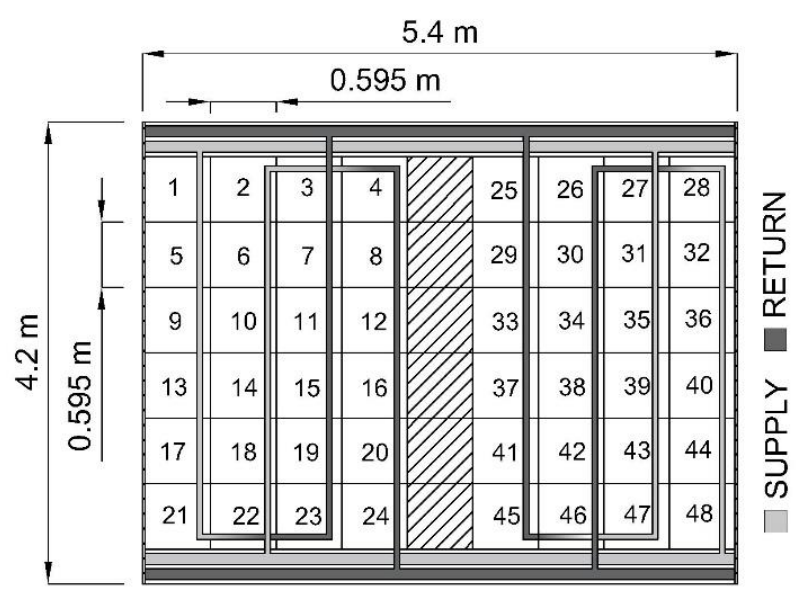

Fig. 4. Pipe network.

After being circulated through the loop present in the suspended ceiling, the water returns to the supply system where it can either be recirculated or can be sent back to the chiller if no temperature regulation is required. A heater was also present in the loop in case the water recirculation was not enough. However, it was never employed. Moreover, within a second loop a mixing valve ensures that cold water is always present close to the pump by allowing a fraction of the flow to be continuously recirculated.

\subsection{Equipment \& sensors}

A set of equipment and sensors were used to monitor the behaviour of the experiment. The parameters monitored were:

- Flow rates, supply and return temperatures of the water circuit (every 15 minutes).

- Surface temperatures of 28 ceiling panels (every 10 seconds with the heat flux sensor and every 5 minutes with the PT1000).

- Heat flux between room and 12 ceiling panels (every 10 seconds). 
Air temperature at different heights and the operative temperature (every 5 minutes) close to the simulated occupants.

The flow rates, supply and return temperatures were monitored on the manifold pipes with a sensor for each side. The temperature sensors were PT500 and had a range between 2 and $180^{\circ} \mathrm{C}$ and an accuracy of $\pm 0.4^{\circ} \mathrm{C}$, while the flow rate sensor had a range between 0 and 0.6 $\mathrm{m}^{3} / \mathrm{h}$ and an accuracy of $\pm 0.14 \%$.

For monitoring the surface temperature, 16 PT1000 class A sensors with a temperature range $-50^{\circ} \mathrm{C}$ to $500^{\circ} \mathrm{C}$ and an accuracy of $\pm 0.2^{\circ} \mathrm{C}$ were used. The PT 1000 were fitted on panels $3,6,9,11,14,16,17,19,22,27,30,33$, $35,38,40,43,46$.

Panels 1, 8, 10, 15, 17, 24, 25, 32, 34, 39, 41 and 48, were equipped with heat flux sensors, which had temperature sensors incorporated. Three smaller ones were used for panels 1,32 and 48 with $50 \times 50 \mathrm{~mm} \mathrm{WxL}$, with a sensitivity around $\pm 0.01 \mathrm{mV} / \mathrm{W} / \mathrm{m}^{2}$. For the other panels, the heat flux sensors were bigger in size, 88x95 $\mathrm{mm} \mathrm{WxL}$ respectively and had a heat flux measurement range of $\pm 150 \mathrm{~kW} / \mathrm{m}^{2}$ with a $\pm 3 \%$ accuracy and a temperature range between $-50^{\circ} \mathrm{C}$ and $120^{\circ} \mathrm{C}$.

Several temperature sensors were also placed on a stand to measure the air temperature at different heights and the operative temperature within the room during the experiment. The air temperature was measured for ankle, abdomen and the head level of a seated person at 0.1, 0.6 and $1.1 \mathrm{~m}$ as well as at the head level of a standing person, $1.7 \mathrm{~m}$. For these, a set of PT1000 sensors surrounded by a cylinder to shield the sensor from radiation were used. In addition, the operative temperature was measured at a height of $0.6 \mathrm{~m}$ with a globe temperature sensor. These heights were chosen according to ISO 7730 [8]. Two such stands were placed behind each occupant, resulting in two sets of data for a better monitoring of the temperature distribution in the room.

\subsection{Ceiling panels}

For the comparison, two commercially available panels were selected. The RCPs, metal panel plus piping system, was considered as reference. The PCM panels were comprised out of gypsum and microencapsulated PCM. Nevertheless, the PCM panels were also fitted with the same piping system, which represented a new combination with respect to the discharging method.

The RCPs were $0.595 \times 0.595 \mathrm{~m}$ WxL ceiling panels, which were mounted onto a suspended ceiling system [9]. These panels were radiative heating/cooling panels (RCP) within which cold or hot water could be circulated in order to maintain an acceptable indoor thermal environment.

The panels consisted of a steel ceiling panel, a copper serpentine pipework, aluminum heat-conducting profile, magnetic strip and a U-mounting rail [9]. The RCPs presented an increased heat conductivity due to the aluminum profile, which maintained good contact with the pipes. Furthermore, the magnetic strips ensured good contact with the sheet steel ceiling panel for a better distribution of heat.
The PCM ceiling panels were a perforated gypsum $0.592 \times 0.592 \times 0.016 \mathrm{~m} \mathrm{WxLxH}$ panel, which contained microencapsulated PCM [10]. For discharging the panels, the same pipe network was used by switching the steel ceiling panel with the PCM panel. Thus, the copper pipes fitted into the heat-conducting profile were resting directly on the gypsum panel. The PCM panel was also equipped with an acoustic fleece on the backside for acoustic purposes, which was not removed as it also had the role of reinforcing the tile.

The role of the PCM panel is to increase the thermal mass of a lightweight building. Nevertheless, in the present paper, the PCM panels are used for absorbing the heat produced by the gains during the day. At night, water was circulated in the pipe network installed for discharging the PCM panel. The PCM panel also presented advantages such as easy mounting because of its simplicity as well as easy cleaning due to the panel's composition. Moreover, the data sheet stated that the panel also improves the indoor climate as it is able to control the moisture content of the room because of the hygroscopic materials used in its construction [10]. The PCM panel had a total heat capacity of $123 \mathrm{Wh} / \mathrm{m}^{2}$ between 10 and $30^{\circ} \mathrm{C}$ and a peak melting temperature of $23^{\circ} \mathrm{C}$.

\subsection{Experimental scenarios}

The purpose of the experiment was to observe the behaviour of the two panels and compare them in terms of the created indoor thermal environment. Two out of the seven scenarios, RCP C and PCM G, did not have water circulation active in order to observe the effect of PCM addition. As the main interest was discharging the panels actively through the piping cooling system, the rest of the cases had the water circulation active. Furthermore, no ventilation strategy was selected throughout the experiments to better identify the effect of the piping cooling system.

Table 2 presents the different scenarios under which the panels were tested with respect to the period, operation schedule, water flow rate, supply water temperature, heat gains and water circulation control.

All experiments were carried out in 2018 with the same internal heat gains (occupants \& equipment). Two solar heat gain settings were used however, referred to as SHG1 and SHG2. SHG1 represents the solar heat gains presented in section 2.1, while SHG2 had $25 \mathrm{~W}$ less at each time step.

In addition, two different controls were selected for the water circulation in the RCP and PCM cases. The water circulation was thus active for the RCP's case during the operation schedule only if the operative temperature was higher than $23^{\circ} \mathrm{C}$. On the other hand, in the PCM case the water circulation was active if both the operative temperature and the average surface temperature of panels $6,14,16,22,27,33,35,43$ were higher than $21^{\circ} \mathrm{C}$ also within the defined schedule. Both controls were selected in order to prevent low indoor temperatures in both mornings and afternoons. 
Table 2. Experimental scenarios.

\begin{tabular}{|c|c|c|c|c|c|c|c|c|}
\hline Panels & Case & Start & End & $\begin{array}{l}\text { Cooling } \\
\text { system } \\
\text { Operation }\end{array}$ & $\begin{array}{c}\text { Flow } \\
\text { Rate } \\
{[\mathrm{kg} / \mathrm{h}]}\end{array}$ & 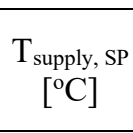 & SHG & $\begin{array}{c}\text { Water } \\
\text { circulation } \\
\text { control }\end{array}$ \\
\hline \multirow[t]{3}{*}{$\mathrm{RCP}$} & A & $22 / 01$ & $26 / 01$ & $08: 00-18: 00$ & 140 & 18 & SHG1 & \multirow{2}{*}{$\mathrm{T}_{\mathrm{op}}>23^{\circ} \mathrm{C}$} \\
\hline & B & $14 / 02$ & $18 / 02$ & $08: 00-18: 00$ & 140 & 18 & SHG2 & \\
\hline & $\mathrm{C}$ & $04 / 08$ & $08 / 08$ & N/A & N/A & N/A & SHG1 & N/A \\
\hline \multirow[t]{4}{*}{ PCM } & D & $18 / 04$ & $24 / 04$ & $18: 00-08: 00$ & 140 & 18 & SHG1 & \multirow{4}{*}{$\begin{array}{c}\mathrm{T}_{\mathrm{op}}>21^{\circ} \mathrm{C} \\
\& \\
\mathrm{~T}_{\text {surf,av }}>21^{\circ} \mathrm{C} \\
\text { N/A }\end{array}$} \\
\hline & $E$ & $26 / 04$ & $04 / 05$ & $18: 00-08: 00$ & 220 & 18 & SHG1 & \\
\hline & $\mathrm{F}$ & $04 / 05$ & $14 / 05$ & 18:00-08:00 & 140 & 18 & SHG2 & \\
\hline & $\mathrm{G}$ & $25 / 07$ & $31 / 07$ & N/A & N/A & N/A & SHG1 & \\
\hline
\end{tabular}

\section{Results}

Both the behaviour and the resulting thermal environment for the RCP and PCM is presented only for the reference cases with active cooling system, A and D.

As there was no difference between the days of the week, i.e. the experiment ran with the same parameters for the entire period analysed, just the second to last day of the period is shown for each case. The choice of taking one of the days towards the end of the experimental period was made in order for the system to achieve steady state. Finally, a comparison is made only with respect to the thermal environment achieved in each scenario.

\subsection{RCP A - $140 \mathrm{~kg} / \mathrm{h} \&$ SHG1}

With the purpose of determining the behaviour of the system and if both the system and sensors were running correctly, a comparison was made (Figure 5) between the heat removed from the room $\left(\mathrm{Q}_{\text {water }}\right)$, the cooling demand $\left(\mathrm{Q}_{\text {demand }}\right)$ and the heat flux between the measured panels and the room (HF - heat flux).

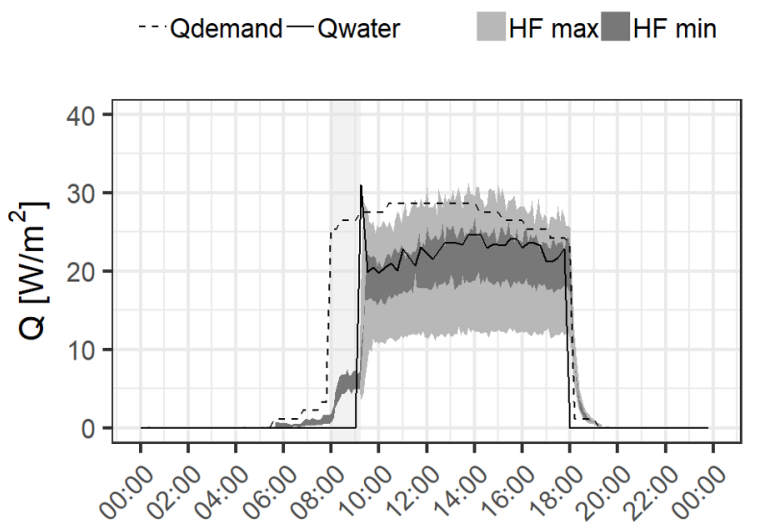

Fig. 5. Qwater, $Q_{\text {demand }}$ and heat flux minimum and maximum band.

The cooling energy demand was increasing from around 05:30 when the sun started to rise. At 08:00 the gains turned on, and thus $\mathrm{Q}_{\text {demand }}$ increased steeply. Nevertheless, a delay was observed (highlighted area) for the water circulation, $\mathrm{Q}_{\text {water }}$. This was due to the water control, as the circulation started only if the operative temperature reached a value higher than $23^{\circ} \mathrm{C}$ (Figure 6). At the end of the operation schedule, 18:00, both the heat gains and water circulation stopped. For the entire occupancy period, a difference was observed between $\mathrm{Q}_{\text {demand }}$ and $\mathrm{Q}_{\text {water }}$ during system operation, which could be attributed to energy stored in the thermal mass of the office and the heat losses to the surroundings.

The heat flux between the surface of the panel and the room followed the same trend as $\mathrm{Q}_{\text {water }}$ during system operation, which further stressed that heat is being removed through the ceiling active system. Two bands are visible in the same figure, HF max and min. Only two of the sensors produced values within the maximum band, number 8 and 48. Their measurements had the highest mean absolute error of $48 \%$ and $25 \%$ respectively in connection with $\mathrm{Q}_{\text {water }}$. The rest of 10 heat flux sensors registered values within a smaller band, HF min, with a mean absolute error between $21 \%$ and $7 \%$ with respect to

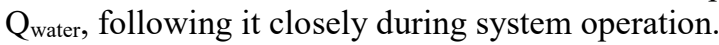

Figure 6 offers a better understanding of the heat exchange between the panels and the room. Here, the operative temperature was plotted against both the temperature and heat flux bands measured by the heat flux sensors.

As both the heat gains and the water circulation were active only during occupancy, the heat flux was highest during that interval. During the same period, as the panels represent the cold surface, a difference was observed between $\mathrm{T}_{\mathrm{op}}$ and the panels' surface temperature.

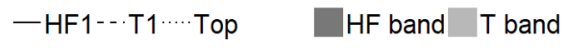

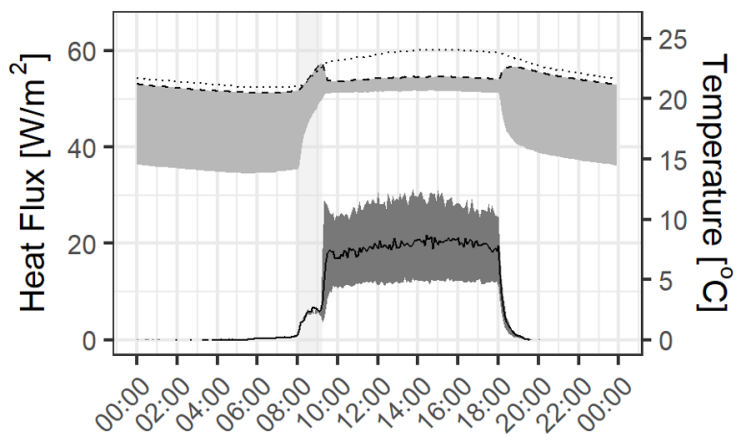

Fig. 6. Heat flux, surface temperatures and operative temperature RCP A.

Figure 6 also exhibits errors in the surface temperature measured by the heat flux sensors outside occupancy, as temperatures reached values as low as $15^{\circ} \mathrm{C}$. However, this inaccuracy occurred only for the some of the sensors. 
In Figure 6, sensor 1 is highlighted for both heat flux and surface temperature as an example. For it the surface temperature fluctuated between 20 and $24^{\circ} \mathrm{C}$, the same range as the PT1000 sensors (Figure 7). In addition, sensor 1 measurements closely followed the operative temperature outside occupancy, which further ensures its precision.

Except for validating the temperature measurements of the heat flux sensors, Figure 7 also shows that the surface temperature of the panels was higher towards the middle of the room, T33, and lower towards the edge, T27.

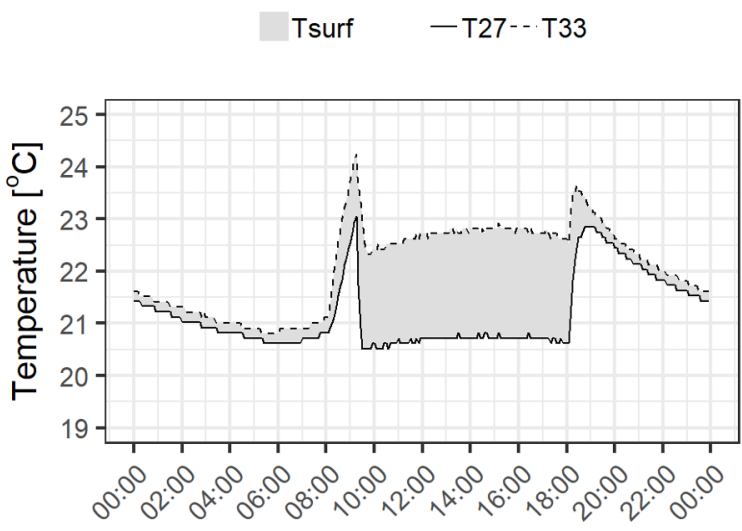

Fig. 7. Surface temperature of panels measured by PT1000 sensors RCP A.

Fig. 8 shows the thermal stratification in the room. The curves represent an average between the two stands as a negligible difference was observed between them.

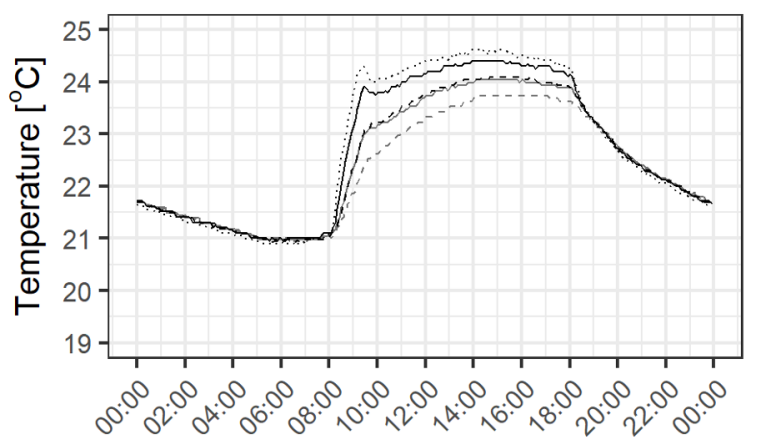

Fig. 8. Average temperatures measured on the stands for RCP A.

The air temperature was lowest at the ankle level $(0.1 \mathrm{~m})$. As the height increased, the temperature increased due to stratification, the air temperature being highest at $1.7 \mathrm{~m}$. The operative temperature closely followed the trend of the air temperature at $0.6 \mathrm{~m}$ as both sensors were placed at the same height, the maximum difference reaching $0.2^{\circ} \mathrm{C}$, while at the same time registering values lower than $25^{\circ} \mathrm{C}$.

Figure 8 also shows that the control employed could have a positive effect on the energy use with little effect on the indoor thermal environment. As $\mathrm{T}_{\text {op }}$ must be higher than $23^{\circ} \mathrm{C}$ for the water circulation to start, energy was saved for more than an hour at the start of occupancy schedule, leading to a decrease in the total pump operation time by $15.6 \%$.

Finally, the maximum vertical air temperature difference was never more than $2^{\circ} \mathrm{C}$ between the ankle and head of a sitting person $(0.1,1.1 \mathrm{~m})$, which was in accordance with the maximum allowable vertical air temperature difference for category A of ISO 7730 [8].

\subsection{PCM D - $140 \mathrm{~kg} / \mathrm{h} \&$ SHG1}

The following section presents the behaviour and resulting thermal environment for the PCM panels experiment, case D $-140 \mathrm{~kg} / \mathrm{h}$ and SHG1. As previously mentioned only the second to last day was analysed. Moreover, in the interest of observing the differences in operation with respect to the RCP case, the same approach was employed.

Figure 9 presents $\mathrm{Q}_{\text {demand, }}, \mathrm{Q}_{\text {water }}$ and the values registered by the heat flux sensors marked by the heat flux band. As no changes were brought to the heat gains profile, $\mathrm{Q}_{\text {demand }}$ followed the same trend as in RCP A case. On the other hand, the cold water circulation had a different schedule, outside of the occupancy period. Thus, water should have had values different from zero only between 18:00 and 08:00. However, this was not the case as water circulation was visible for the first hour of the day.

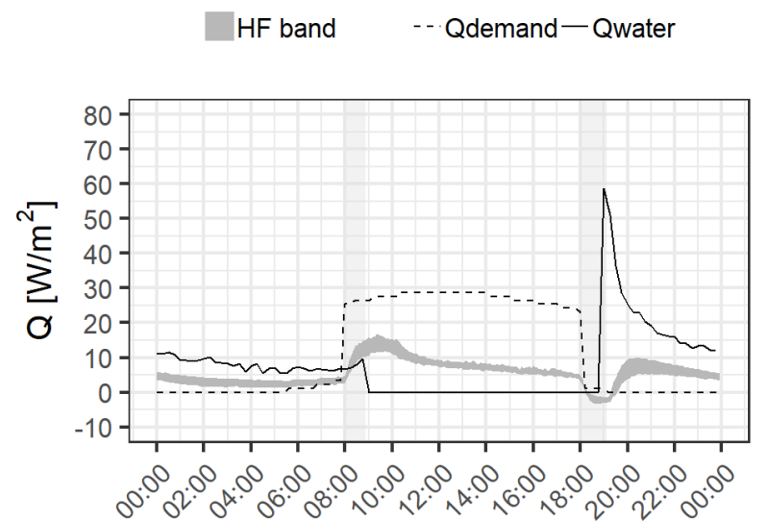

Fig. 9. Qwater, Qdemand and heat flux band.

Nevertheless, a 1-hour delay also occured in the evening, from 17:00 to 18:00. Thus, a shift of approximately 1 hour was observed for $\mathrm{Q}_{\text {water }}$ (highlighted areas), which could be attributed to the time change in March and not to the malfunction of the control, as the error was not present for the RCP cases. Nonetheless, this does not affect the results of the experiment.

The heat flux band still followed the $\mathrm{Q}_{\text {water }}$ curve outside of occupancy, but it registered values also during occupancy when water circulation was not active. Thus, the heat flux was distributed over the entire day. This phenomenon appeared due to the added thermal mass of the PCM, which allowed for the absorption of heat during the day. However, the heat flux registered considerable lower values than $Q_{\text {demand }}$ during occupancy as opposed to the RCP, suggesting that the heat capacity of the PCM was not enough to absorb the extra heat.

Two peaks are visible in the heat flux, during 
morning when occupancy started and in the evening in both Figures 9 and 10. These represented the charging and discharging periods of the PCM, highlighted with grey areas in Figure 10. The surface temperatures measured by the heat flux sensors (Figure 10) and by the PT1000 (Figure 11) further confirmed this observation for the charging phase as they show temperatures in the range $21^{\circ} \mathrm{C}$ to $24^{\circ} \mathrm{C}$, which matched the range given in the datasheet of the PCM [8]. Furthermore, during these two phases, flatter slopes were visible in the surface temperature curves.

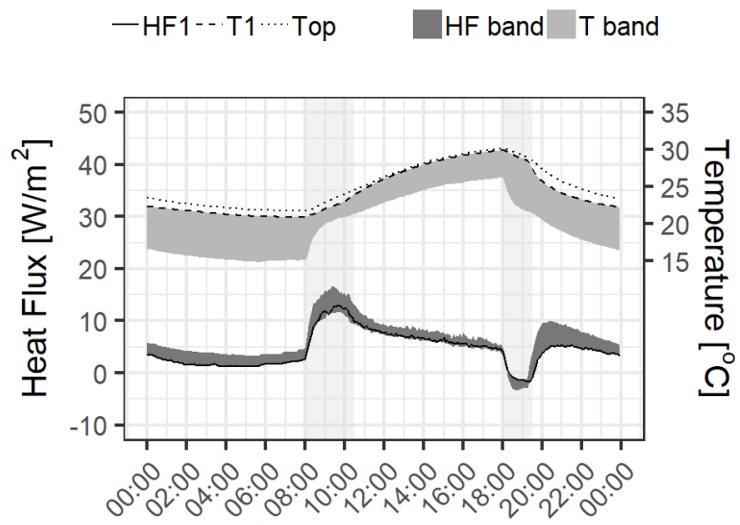

Fig. 10. Heat flux and surface temperatures and operative temperature PCM D.

Still, the heat flux peak in the evening was negative, with surface temperatures between $28^{\circ} \mathrm{C}$ and $32^{\circ} \mathrm{C}$, far from the range presented in the datasheet. This was a consequence of the pipe placement, over the PCM panel. As water circulation started, the top part of the PCM panel released heat towards the pipes. On the other hand, heat was released from the bottom part of the PCM panel to the room, which was slightly cooler than the surface of the panels, therefore resulting in a negative heat flux.

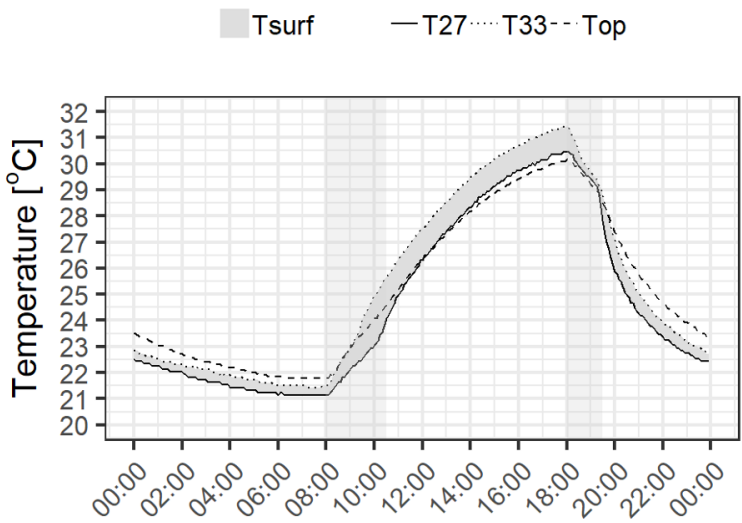

Fig. 11. Surface temperature of panels measured by PT1000 sensors PCM D.

The previous assumption was not supported by the surface temperatures measurements by the heat flux sensors (Figure 10). However, the surface temperatures measurements of some heat flux sensors have previously shown errors in the RCP scenario, confirmed by the low temperatures registered in this case as well, outside of occupancy (Figure 10). Nevertheless, the heat flux measurements have always followed the values of heat removed by the circulating water (Figures 5 and 9). Moreover, although on different panels, the PT1000 (Figure 11) showed that the surface temperature of the panels was higher than the operative temperature, which would further explain the negative heat flux in the evening.

The surface temperatures presented the same effect as in the RCP cases, a higher temperature of the ceiling closer to the localized heat gains (T33), and lower towards the edge (T27). Still, as expected, PCM D presented a poorer indoor thermal environment, with operative temperatures as high as $31.5^{\circ} \mathrm{C}$ towards the end of occupancy period.

The thermal stratification is again presented in Figure 12 as an average between the two stands. The operative temperature was not satisfactory, as it quickly exceeded $26^{\circ} \mathrm{C}(11: 30)$, the upper limit for Category II operative temperature for cooling season, in approximately 3 hours from occupancy start [11].

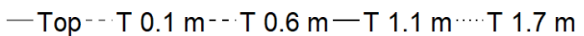

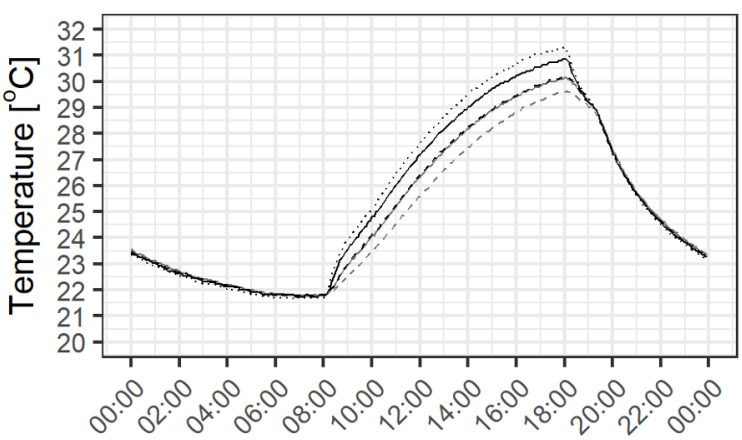

Fig. 12. Average temperatures measured on the stands for PCM D.

Temperature stratification was observed here as well, with lowest values for the ankle level and highest for 1.7 $\mathrm{m}$. As the air temperature at $0.6 \mathrm{~m}$ and the operative temperature are both taken at the same heights, the two presented little differences. Moreover, for the duration of the experiment, the maximum vertical air temperature difference between the ankle and head of a sitting person $(0.1,1.1 \mathrm{~m})$ for the analysed day, $23^{\text {rd }}$ of April, was less than $2^{\circ} \mathrm{C}$ for both occupants, being in the recommended range of Category A of ISO 7730 [8].

\subsection{RCP vs. PCM}

According to EN 15251, for offices and similar spaces, there are three temperature ranges defined in relationship to the building category. For Category I, Category II, and Category III offices, a temperature range between $23.5^{\circ} \mathrm{C}$ and $25.5^{\circ} \mathrm{C}, 23^{\circ} \mathrm{C}$ to $26^{\circ} \mathrm{C}$ and $22^{\circ} \mathrm{C}$ to $27^{\circ} \mathrm{C}$ is recommended [11].

Table 3 shows, by scenario, the percentages of time from the occupancy periods when the operative temperature was within the limits for each case. It can be observed that the best performing scenario was when the radiant cooling panels were employed with a flow rate of $140 \mathrm{~kg} / \mathrm{h}, \mathrm{RCP} \mathrm{A}$, in which the operative temperature was within $22^{\circ} \mathrm{C}$ and $27^{\circ} \mathrm{C}$ (Category III) for $91 \%$ of the 
Table 3. Percentages of occupancy periods when operative temperature was within EN 15251 limits for the office room by case.

\begin{tabular}{|c|c|c|c|c|c|c|}
\hline \multirow{2}{*}{ Panel } & Scenario & Flow rate $[\mathrm{kg} / \mathrm{h}]$ & SHG & $\begin{array}{c}\text { Category I } \\
{[\%]}\end{array}$ & $\begin{array}{c}\text { Category II } \\
{[\%]}\end{array}$ & $\begin{array}{c}\text { Category III } \\
{[\%]}\end{array}$ \\
\hline \multirow{3}{*}{ RCP } & A & 140 & SHG 1 & 57 & 75 & $\mathbf{9 1}$ \\
\cline { 2 - 7 } & B & 140 & SHG 2 & 0 & 0 & 75 \\
\cline { 2 - 7 } & C & N/A & SHG 1 & 0 & 0 & 0 \\
\hline \multirow{3}{*}{ PCM } & D & 140 & SHG 1 & 17 & 26 & 44 \\
\cline { 2 - 7 } & E & 220 & SHG 1 & 19 & 30 & 48 \\
\cline { 2 - 7 } & F & SHG 2 & 17 & 27 & 43 \\
\hline
\end{tabular}

occupancy time. However, it is important to mention, that for this analysis, the first three days of case RCP A were not taken into consideration as the system was not running within normal parameters.

The PCM panels did best in the second scenario, PCM E, reaching category III for $48 \%$ of the time because of the increased flow rate. Scenarios PCM D and F are very close, even though the solar heat gains were reduced by $25 \mathrm{~W}$ for the latter. This was because the two experiments ran in different periods, the second one, PCM E case, from the 4th to the 14th of May, registering higher outdoor temperatures.

The reference cases without active cooling system were never within any of the categories presented. However, for similar outside temperatures, the PCM panels presented a smaller operative temperature during the day, reducing the peak by $0.6^{\circ} \mathrm{C}$. Still, the indoor thermal environment benefited more from the active cooling system in both systems.

\section{Discussion}

The main differences found in the operation of the RCP and the PCM panels was the heat flux distribution over the day. This was a consequence of the added thermal mass and the control strategy. However, the aim was to store the extra heat using the thermal mass of the PCM panels during occupancy while discharging only during the night. Thus, the modification in control strategy was required.

First of all, the presence of a multitude of sensors placed on a selection of panels could prove beneficial for future experiments. For example, a surface temperature sensor on the top side of the panels would give a better overview on the accuracy of the results.

Another important aspect of the study was that the experiments were made without ventilation, which would be employed in reality. Its addition would nevertheless have influences on the indoor thermal comfort, while good planning of the system would also help with the distribution of the heat within the room and the overall cooling, thus dividing the heat gains over the area of the ceiling as equally as possible. The addition of ventilation would also provide benefits in the PCM scenarios, as the manufacturer suggests that air should be supplied in the plenum, which would then pass through the openings in the panel, supplying air into the room while at the same time providing benefits in the discharge process.
With respect to the RCP B scenario, a decrease in solar heat gains of $25 \mathrm{~W}$ led to an inferior indoor thermal environment. In that case, the RCPs provided too much cooling, the operative temperature being always lower than $23^{\circ} \mathrm{C}$, thus never achieving a better indoor thermal environment than Category III. Nevertheless, reducing the solar heat gains by $25 \mathrm{~W}$ led to an increase of $49 \%$ of occupancy time when no cooling is required and thus to a decrease in energy use. This means that by using better windows or shading systems, which can reduce the solar heat gains, could result in lower energy use and lower peaks in the operative temperature during the day.

Overheating (too high room temperatures) was observed for all PCM scenarios, within which the operative temperature was always less than $50 \%$ in Category III. However, increasing the flow rate to 220 $\mathrm{kg} / \mathrm{h}$ from $140 \mathrm{~kg} / \mathrm{h}$ (PCM D vs. E) improved the thermal indoor environment, as the operative temperature decreased on average with $0.8^{\circ} \mathrm{C}$ during occupancy. Also, the operative temperature reached $25^{\circ} \mathrm{C}$ at $12: 10,1$ hour and 5 minutes later than for PCM D. Meanwhile, lowering the solar heat gains by $25 \mathrm{~W}$, PCM F, showed an average increase in operative temperature by $0.7^{\circ} \mathrm{C}$ during occupancy, which should not occur. This was due to the surrounding air temperature, which fluctuated from one experiment to the other.

Investigations are required with respect to the necessary quantity of PCM in order to provide an acceptable indoor thermal environment. Increasing the flow rate or running multiple water circulations during the day could bring improvements with respect to this problem, but that was not the aim of this study. Furthermore, improvements are required with respect to the construction of the PCM panel if discharging would be made through water circulated in the pipes. For a better discharge, the pipes should be embedded in the panels allowing for an even distribution of heat on the axis parallel to the thickness of the panel.

In reality the system should have the possibility of regulating the water flow rate. Through it, the system could provide the required cooling in order to maintain the system within the desired parameters for any scenario. Lastly, the RCP and PCM panels were investigated in different seasons. Considering the room integrity issue, the results from the two panels were influenced, which could mean that their ability of providing an acceptable indoor thermal environment might be closer than the one presented. 


\section{Conclusion}

As expected, considering the maturity of the technology, the radiant cooling panels were able to maintain a better thermal indoor environment than the PCM panels for the active cooling system scenarios, RCP A and PCM E. According to EN 15251:2007, both panels performed best in Category III where the operative temperature was between $22^{\circ} \mathrm{C}$ and $27^{\circ} \mathrm{C}$ for $91 \%$ of the time in the RCP A case, while only $48 \%$ of the time for the PCM case E. For Category II of the same standard, the operative temperature was within the range $23^{\circ} \mathrm{C}$ to $26^{\circ} \mathrm{C}$ for only $75 \%$ and $30 \%$ respectively for the same scenarios.

The PCM panel presented the ability to store the heat for a later time but due to its low capacity, the charging was completed in 2.5 hours leading to operative temperatures as high as $31.5^{\circ} \mathrm{C}$ in the room before the occupancy period ended. Also, while comparing the two reference cases without active cooling, a reduction was observed in the peak temperature during occupancy.

The temperature stratification was within normal parameters for all cases. According to ISO 7730 the vertical temperature between the ankles and head of a sitting person never reached values higher than $2^{\circ} \mathrm{C}$, being always within Category A [8]. Finally, the addition of shading systems and the installation of better windows can increase the energy savings from cooling as well as lower peaks in the operative temperature during the day.

\section{Acknowledgements}

This study was financially supported by the European Union's Horizon 2020 research and innovation programme under grant agreement No. 723649, the Nordic Build Project "Low Temperature Heating and High Temperature Cooling in Refurbishment and New Construction of Buildings" No. NB13339 and by the International Centre for Indoor Environment and Energy (ICIEE), Technical University of Denmark (DTU). The authors would like to thank Nico Henrik Ziersen for his help with preparing the experimental setup and Uponor for providing materials.

\section{References}

1. S. E. Kalnæs, B. P. Jelle, Phase change materials and products for building applications: A state-of-the-art review and future research opportunities, Energy Build. 94, 150-176 (2015)

2. F. Tie-lin, Z. Feng-qing, Application of Phase Change Materials in Buildings, Adv. Mater. Res. 1096, 533-537 (2015)

3. M. Koschenz, B. Lehmann, Development of a thermally activated ceiling panel with PCM for application in lightweight and retrofitted buildings, Energy Build. 36, 567-578 (2004)

4. L. Derradji, F. Errebai, M. Amara, Effect of PCM in Improving the Thermal Comfort in Buildings, Energy Procedia 107, 157-161 (2016)
5. E. Bourdakis, O. B. Kazanci, F. Grossule, B. W. Olesen, Simulation Study of Discharging PCM Ceiling Panels through Night-time Radiative Cooling, CLIMA 2016, (2016)

6. E. Bourdakis, O.B. Kazanci, T.Q. Péan, B. W. Olesen, Parametric Analysis of the Operation of Nocturnal Radiative Cooling Panels Coupled with in Room PCM Ceiling Panels, ASHRAE 2017, (2017)

7. ASHRAE, Weather Data by Region, https://energyplus.net/weatherregion/europe_wmo_region_6, (accessed 21/04/2018)

8. Danish Standards Association, Ergonomics of the thermal environment - Analytical determination and interpretation of thermal comfort using calculation of the PMV and PPD indices and local thermal comfort criteria, DS/EN ISO 7730, (2006)

9. Uponor, Uponor Download Centre, https://www.uponor.co.uk/services/downloadcentre?q=spectra, (accessed 7/11/2018)

10. ThermaCool, ThermaCool Tile, http://therma.cool/products/thermacool-tile/, (accessed 7/11/2018)

11. Danish Standards Association, Indoor environmental input parameters for design and assessment of energy performance of buildings addressing indoor air quality, thermal environment, lighting and acoustics, DS/EN 15251, (2007) 